\title{
Lifestyle factors and contact to general practice with respiratory alarm symptoms - a population-based study
}

\author{
Lisa Maria Falk Sele*, Sandra Elnegaard, Kirubakaran Balasubramaniam, Jens Søndergaard and Dorte Ejg Jarbøl
}

\begin{abstract}
Background: A prerequisite for early lung cancer diagnosis is that individuals with respiratory alarm symptoms (RAS) contact a general practitioner (GP). This study aims to determine the proportion of individuals in the general population who contact a GP with RAS and to analyse the association between lifestyle factors and contact to GPs with RAS.
\end{abstract}

Methods: A web-based survey of 100000 individuals randomly selected from the Danish Civil Registration System. Items regarding experience of RAS (prolonged coughing, shortness of breath, coughing up blood, and prolonged hoarseness), GP contacts, and lifestyle factors (smoking status, alcohol intake, and body mass index) were included.

Results: In total 49706 (52.5\%) individuals answered the questionnaire. Overall 7870 reported at least one respiratory alarm symptom, and of those $39.6 \%$ (3 080) had contacted a GP. Regarding specific symptoms, the proportion of individuals that had contacted a GP varied from $27.4 \%$ (prolonged hoarseness) to $47.9 \%$ (shortness of breath). Being a woman and increasing age were significantly associated with a higher proportion of GP contacts. For both genders, current smoking and alcohol intake were significantly associated with lower odds of contacting a GP.

Conclusion: Among individuals with RAS, less than one-half contacted a GP. Gender, age, smoking status, and alcohol intake significantly influenced whether individuals with RAS contacted a GP.

Trial registration: The project has been approved by the Danish Data Protection Agency (journal no. 2011-41-6651).

Keywords: Lung cancer, Symptoms, Healthcare seeking, Lifestyle factors, General population

\section{Background}

Lung cancer is the most common cause of cancerrelated death worldwide [1]. Among other factors, stage at diagnosis has been associated with poor survival rates $[2,3]$. To diagnose lung cancer at an earlier stage and to optimise the diagnostic process, cancer referral guidelines have been introduced $[4,5]$. The lung cancer guidelines define a number of respiratory alarm symptoms (RAS) indicative of lung cancer [6, 7]. Suspicion of lung cancer is most often raised in general practice [8-10] and general practitioners (GPs) are recommended to refer patients reporting RAS for further investigation $[6,7]$. However, one prerequisite for GPs to be able

\footnotetext{
* Correspondence: Isele@health.sdu.dk

Research Unit of General Practice, Department of Public Health, University of Southern Denmark, J.B. Winsløws Vej 9A, 5000 Odense C, Denmark
}

to refer patients with RAS is that individuals with RAS contact a GP.

Current knowledge about the interval from the first symptom experience to GP contact is based mainly on retrospective studies conducted among selected groups of patients already diagnosed with lung cancer, and may thus be flawed by recall bias. The literature points to the fact that RAS arise long before presentation to the GP $[11,12]$. Multiple factors may affect people's decisions about healthcare seeking [13, 14]. Little is, however, known about individuals with RAS and contact to general practice.

Factors that might affect the decision to contact a GP with RAS include socioeconomic status, experience with illness, and lifestyle factors (e.g., smoking status, alcohol intake, and body mass index (BMI)). Both smoking and 
alcohol intake have been associated with a prolonged interval from symptom experience to diagnosis in head and neck cancers [15], and smoking in particular has been highlighted as a reason for having postponed GP contact among patients with lung cancer [16, 17]. An enhanced understanding of healthcare seeking behaviour in the general population, may improve policy interventions targeting health care seeking with RAS in different groups.

The objectives of this study were to determine the proportion of individuals in the general Danish population, who contact a GP with RAS and to analyse the association between lifestyle factors and contact to GPs with RAS.

\section{Methods}

\section{Study design and population}

The study was designed as a nationwide cohort study of 100000 adults aged 20 years or older, randomly selected from the general population. The project was approved by the Danish Health Authority, who provided a random sample from the Danish Civil Registration System (CRS), where all Danish citizens are registered with a unique personal identification number. The CRS contains information on every Danish resident's date of birth, gender, migration, etc. [18]. Each invited individual received a postal letter explaining the purpose of the study. The letter also contained a unique 12-digit login for a secure webpage. This provided access to a web-based questionnaire about health, symptoms, and GP contacts. Individuals without access to a computer, tablet, or smartphone were offered the opportunity to complete the survey as a telephone interview.

\section{The questionnaire}

A comprehensive questionnaire concerning the experience of 44 predefined specific and nonspecific cancer alarm symptoms, as well as general and frequent symptoms, was developed. The alarm symptoms were selected based on a review of literature including national and international cancer referral guidelines $[6,7,10,19]$. This paper focus on four RAS: prolonged coughing, shortness of breath, coughing up blood, and prolonged hoarseness [7]. The questionnaire was based on standard rating scales, previously validated questionnaires, and ad hoc items. The methodological framework for developing, pilot testing, and field testing the questionnaire is described in detail elsewhere [20].

The respondents were asked whether they had experienced one or more of the symptoms within the preceding four weeks, and whether they had contacted a GP about the symptom(s). The wording of the question regarding symptoms was: "Have you experienced any of the following bodily sensations, symptoms, or discomforts within the past four weeks? (Tick off yes for each positive answer)" The question regarding contacting a GP was: "Have you contacted your GP concerning the symptom(s) you have experienced within the preceding four weeks, through appointment, by telephone, or email? (Yes/no)".

An item concerning when the symptom(s) first occurred was also included. The response categories were: "Less than one month ago", "1-3 months ago", "3-6 months ago" or "more than six months ago". Questions regarding current smoking status, average alcohol intake, weight, and height were also asked.

\section{Statistical analyses}

In the lung cancer referral guideline, coughing and hoarseness are defined as alarm symptoms when prolonged, i.e., when lasting for more than 4 to 6 weeks and 3 to 4 weeks, respectively [7]. To comply with these definitions, only respondents who first experienced the symptom more than one month ago were considered to have experienced prolonged coughing and prolonged hoarseness.

Covariates considered in the uni- and multivariate statistical analyses were gender, age, smoking status, alcohol intake, and BMI. The respondents were divided into the following age groups: $20-39,40-59,60-79$, and $\geq 80$ years. Smoking status was categorised as current, former, and never smokers. Alcohol intake was categorised according to units per week: $0,1-7,8-21$, and $\geq$ 22 units/week. BMI was calculated from height and weight, and categorised according to the World Health Organization guidelines [21]: underweight (BMI <18.5), normal weight (BMI 18.5-24.9), overweight (BMI 2529.9), and obese (BMI $\geq 30$ ).

We calculated the proportion of individuals who contacted a GP with at least one of the RAS, as well as the proportion of individuals who contacted a GP with each of the RAS. Confidence intervals were calculated using the binomial distribution. Differences between the proportion of individuals with RAS that contacted a GP and each covariate were tested with either the chi-squared test or Fisher's exact test, as appropriate.

Multivariate logistic regression models were used to analyse associations between lifestyle factors and contact to GP with RAS. Adjustments were made for possible confounders: age, smoking status, alcohol intake, and BMI [22, 23]. To evaluate collinearity between lifestyle factors, correlation coefficients were calculated with Spearman's rank correlation.

Logistic regression was used to test for interaction between gender and each covariate for contact to GP with at least one respiratory alarm symptom, prolonged coughing, shortness of breath, or prolonged hoarseness, 
respectively. The tests were made with Bonferroni adjustment to account for multiple testing. Tests for interaction and multivariate logistic regression models were not made for coughing up blood because of the small number of respondents with this symptom who contacted a GP. As a result of statistical interactions, the multivariate analyses were stratified with respect to gender.

Linear trends in contacting a GP to report RAS were tested with logistic regression models for age and alcohol intake. All analyses were repeated with the subgroup of people aged 40 and older, owing to the higher risk of lung cancer in this age group.

Statistical tests were made using significance threshold 0.05. Data analyses were conducted using Stata IC 13॰.

\section{Results}

Of the 100000 invited individuals, 4747 (4.7\%) were ineligible because they had died, could not be reached (address unknown), were suffering from severe illnesses (including dementia), had language problems, or had moved abroad. Of the 95253 (95.3\%) eligible individuals, 49706 individuals completed the questionnaire, yielding an overall response rate of $52.2 \%$ (Fig. 1). The median age of the respondents was 52 years (interquartile range (IQR) 40-64) compared to 50 years (IQR 3666) for non-respondents. Slightly more respondents were women (53.2\%). Table 1 lists the descriptive data of the respondents.
Table 1 Characteristics of the respondents

\begin{tabular}{|c|c|c|}
\hline & Number & Percent \\
\hline Total & 49706 & 100.0 \\
\hline \multicolumn{3}{|l|}{ Gender } \\
\hline Men & 23240 & 46.8 \\
\hline Women & 26466 & 53.2 \\
\hline \multicolumn{3}{|l|}{ Age } \\
\hline 20-39 & 12251 & 24.6 \\
\hline $40-59$ & 20305 & 40.9 \\
\hline $60-79$ & 15748 & 31.7 \\
\hline$>80$ & 1402 & 2.8 \\
\hline \multicolumn{3}{|l|}{ Smoking status* } \\
\hline Never & 21895 & 45.9 \\
\hline Former & 15529 & 32.5 \\
\hline Current & 2082 & 21.6 \\
\hline \multicolumn{3}{|l|}{ Alcohol intake* } \\
\hline 0 units/week & 3668 & 7.7 \\
\hline 1-7 units/week & 23321 & 66.3 \\
\hline 8-21 units/week & 10708 & 22.4 \\
\hline$\geq 22$ units/week & 1729 & 3.6 \\
\hline \multicolumn{3}{|l|}{ Body Mass Index* } \\
\hline Underweight (<18.5) & 756 & 1.6 \\
\hline Normal (18.5-24.9) & 23168 & 48.7 \\
\hline Overweight (25-29.9) & 16668 & 35.0 \\
\hline Obese $(\geq 30)$ & 6990 & 14.7 \\
\hline
\end{tabular}

*Total numbers for each group may not add to full sample due to missings
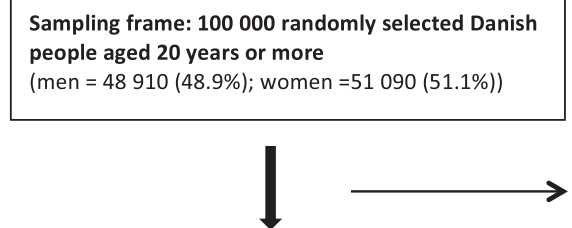

Eligible for the study: 95253 (95.3\%)

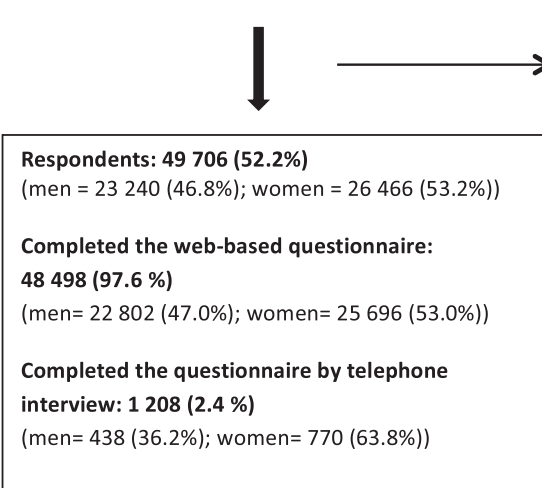

Excluded: $4747(4.7 \%)$

Dead: 315

Addresses unknown: 961

Suffering from severe illness (including dementia): 1972

Language problems: 885

Moved abroad: 614

Non-respondents: 45547 (47.8\%)

$(m e n=23407(51.4 \%)$, women $=22,140(48.6 \%)$

Not wishing to participate (indicated by telephone/email or postal contact): 25690

Indicated 'other reasons' for non-participation: 318

Questionnaire not completed (no achieved contact in the reminder procedure): 19539

Fig. 1 Study cohort 
Tables 2 and 3 depict the proportion of individuals who contacted a GP with at least one respiratory alarm symptom and with each individual respiratory alarm symptom, respectively. Of those reporting at least one respiratory alarm symptom, 39.6 \% had contacted a GP (Table 2). The greatest proportion of contact to a GP were found for shortness of breath $(49.7 \%)$, and the smallest proportion of contact to a GP were found for prolonged hoarseness (27.4 \%) (Table 3).

A significantly higher proportion of women had contacted a GP with at least one respiratory alarm symptom $(p=0.047)$ (Table 2). The difference between genders persisted when analysing prolonged coughing and shortness of breath separately (Table 3). The proportion of individuals who had contacted a GP differed significantly with regard to age group $(p<0.001)$ and smoking status $(p<0.001)$ for all RAS except coughing up blood (Tables 2 and 3). The proportion of individuals who reported GP contact was higher among people in the oldest age groups for all RAS except prolonged hoarseness. Former and never smokers reported higher proportion of GP contact for three of the four RAS when compared to current smokers. No significant differences were found between GP contact, BMI and alcohol intake except for individuals reporting prolonged coughing.

Tables 4 and 5 demonstrate the associations between age, lifestyle factors, and contacting a GP with at least one respiratory alarm symptom, prolonged coughing, shortness of breath and prolonged hoarseness, for men and women, respectively. Due to Interactions between gender and some covariates regarding contact to GP with RAS the analyses were carried out separately for men and women. Analyses regarding coughing up blood were not possible due to few GP contacts. Lifestyle factors were included in the same multivariate logistic regression model because of low correlation coefficients (data not shown).

Table 2 Proportion of contacts to GP with at least one respiratory alarm symptom by gender, age, smoking status, alcohol intake and body mass index

\begin{tabular}{|c|c|c|c|c|c|}
\hline & \multirow{2}{*}{$\begin{array}{l}\text { Symptom experience } \\
n\end{array}$} & \multicolumn{4}{|c|}{ Contact to GP } \\
\hline & & $\bar{n}$ & $\%^{*}$ & $95 \% \mathrm{Cl}$ & $P$-value \\
\hline Total & 7870 & 3080 & 39.6 & $38.5-40.7$ & \\
\hline Gender & & & & & 0.047 \\
\hline Men & 3978 & 1483 & 38.5 & $37.7-40.1$ & \\
\hline Women & 3892 & 1597 & 40.7 & $39.2-42.3$ & \\
\hline Age & & & & & $<0.001$ \\
\hline $20-39$ & 1643 & 435 & 26.7 & $24.6-29.0$ & \\
\hline $40-59$ & 2794 & 989 & 35.6 & $33.8-37.4$ & \\
\hline $60-79$ & 3044 & 1462 & 48.7 & $46.9-50.3$ & \\
\hline$>80$ & 389 & 194 & 52.7 & $47.5-50.5$ & \\
\hline Smoking status & & & & & $<0.001$ \\
\hline Never & 2480 & 979 & 39.5 & $37.5-41.4$ & \\
\hline Former & 2488 & 1196 & 48.1 & $46.1-50.1$ & \\
\hline Current & 2519 & 788 & 31.3 & $29.5-33.1$ & \\
\hline Alcohol intake & & & & & $<0.001$ \\
\hline 0 units/week & 813 & 383 & 47.1 & $43.6-50.6$ & \\
\hline 1-7 units/week & 3114 & 1750 & 39.5 & $38.0-40.9$ & \\
\hline 8-21 units/week & 1828 & 685 & 37.5 & $35.2-39.7$ & \\
\hline$\geq 22$ units/week & 409 & 144 & 35.2 & $30.6-40.1$ & \\
\hline Body Mass Index & & & & & $<0.001$ \\
\hline Underweight $(<18.5)$ & 154 & 64 & 41.6 & $33.7-49.8$ & \\
\hline Normal (18.5-24.9) & 3214 & 1201 & 37.4 & $35.7-39.1$ & \\
\hline Overweight (25-29.9) & 2644 & 1048 & 39.6 & $37.8-41.5$ & \\
\hline Obese $(\geq 30)$ & 1435 & 631 & 44.0 & $41.4-46.6$ & \\
\hline
\end{tabular}

${ }^{a}$ Tested for difference between groups with chi-square test

*Percentages might not fully match to total numbers due to missings. Missings do not exceed $1 \%$ 
Table 3 Proportions of contact to GP with respiratory alarm symptoms by gender, age, smoking status, alcohol intake and BMl

\begin{tabular}{|c|c|c|c|c|c|c|c|c|c|c|c|c|c|c|c|c|c|c|c|c|}
\hline & \multicolumn{5}{|c|}{ Prolonged coughing } & \multicolumn{5}{|c|}{ Shortness of breath } & \multicolumn{5}{|c|}{ Coughing up blood } & \multicolumn{5}{|c|}{ Prolonged hoarseness } \\
\hline & \multirow{2}{*}{$\begin{array}{l}\text { Symptom } \\
\text { experience } \\
n\end{array}$} & \multicolumn{4}{|c|}{ Contact to GP } & \multirow{2}{*}{$\begin{array}{l}\text { Symptom } \\
\text { experience } \\
n\end{array}$} & \multicolumn{4}{|c|}{ Contact to GP } & \multirow{2}{*}{$\begin{array}{l}\text { Symptom } \\
\text { experience } \\
n\end{array}$} & \multicolumn{4}{|c|}{ Contact to GP } & \multirow{2}{*}{$\begin{array}{l}\text { Symptom } \\
\text { experience } \\
n\end{array}$} & \multicolumn{4}{|c|}{ Contact to GP } \\
\hline & & $\bar{n}$ & $\%^{*}$ & $95 \% \mathrm{Cl}$ & $P$-value & & $\bar{n}$ & $\%^{*}$ & $95 \% \mathrm{Cl}$ & $P$-value ${ }^{a}$ & & $n$ & \%* & $95 \% \mathrm{Cl}$ & $P$-value ${ }^{b}$ & & $n$ & $\%^{*}$ & $95 \% \mathrm{Cl}$ & $P$-value ${ }^{a}$ \\
\hline Total & 4180 & 1438 & 34.7 & $33.2-36.7$ & & 3960 & 1936 & 49.7 & $48.1-51.3$ & & 62 & 29 & 47.5 & $34.6-60.7$ & & 1694 & 458 & 27.4 & $25.2-29.6$ & \\
\hline Gender & & & & & $<0.001$ & & & & & $<0.001$ & & & & & 0.586 & & & & & 0.274 \\
\hline Men & 2095 & 658 & 31.7 & $29.7-33.8$ & & 1912 & 960 & 50.9 & $48.6-53.2$ & & 42 & 18 & 43.9 & $28.5-60.3$ & & 813 & 210 & 26.1 & $23.1-29.3$ & \\
\hline Women & 2085 & 780 & 37.7 & $35.6-39.8$ & & 2048 & 976 & 48.5 & $46.3-50.7$ & & 20 & 11 & 55.0 & $31.5-76.9$ & & 881 & 248 & 28.5 & $25.5-31.6$ & \\
\hline Age & & & & & $<0.001$ & & & & & $<0.001$ & & & & & 0.295 & & & & & $<0.001$ \\
\hline $20-39$ & 813 & 184 & 22.9 & $20.0-25.9$ & & 880 & 288 & 33.1 & $29.9-36.3$ & & 18 & 8 & 44.4 & $21.5-69.2$ & & 303 & 32 & 10.7 & $7.4-14.7$ & \\
\hline $40-59$ & 1452 & 435 & 30.0 & $27.6-32.4$ & & 1423 & 632 & 44.8 & $42.2-47.5$ & & 23 & 8 & 36.4 & $17.2-59.3$ & & 519 & 136 & 26.4 & $22.6-30.4$ & \\
\hline $60-79$ & 1696 & 723 & 43.0 & $40.7-45.4$ & & 1457 & 883 & 61.8 & $59.2-64.3$ & & 23 & 12 & 60.0 & $36.1-80.1$ & & 750 & 251 & 34.1 & $30.7-37.7$ & \\
\hline$>80$ & 219 & 96 & 45.7 & $38.9-52.7$ & & 200 & 133 & 71.1 & $64.1-77.5$ & & $1^{* *}$ & 1 & 100.0 & $36.1-80.1$ & & 122 & 39 & 32.0 & $23.8-41.0$ & \\
\hline Smoking status & & & & & $<0.001$ & & & & & $<0.001$ & & & & & 0.340 & & & & & $<0.001$ \\
\hline Never & 1262 & 482 & 38.2 & $35.5-40.9$ & & 1224 & 562 & 45.9 & $43.1-48.8$ & & 19 & 7 & 36.8 & $16.3-61.6$ & & 567 & 165 & 29.1 & $25.4-33.0$ & \\
\hline Former & 1097 & 471 & 42.9 & $40.0-45.9$ & & 1387 & 809 & 58.3 & $55.7-60.9$ & & 20 & 12 & 60.0 & $36.1-80.9$ & & 617 & 193 & 31.3 & $27.6-35.1$ & \\
\hline Current & 1635 & 428 & 26.2 & $24.1-28.4$ & & 1131 & 490 & 43.3 & $40.4-46.3$ & & 18 & 10 & 55.6 & $30.8-78.5$ & & 430 & 88 & 20.5 & $16.7-24.6$ & \\
\hline Alcohol intake & & & & & $<0.001$ & & & & & 0.142 & & & & & 0.281 & & & & & 0.239 \\
\hline 0 units/week & 409 & 175 & 42.8 & $37.9-47.7$ & & 489 & 267 & 45.6 & $50.1-59.1$ & & 7 & 5 & 71.4 & 23.9-96.3 & & 167 & 53 & 31.7 & $24.8-39.4$ & \\
\hline $\begin{array}{l}1-7 \\
\text { units/week }\end{array}$ & 1642 & 806 & 35.2 & $33.2-37.2$ & & 1510 & 1105 & 48.9 & $46.9-51.0$ & & 25 & 19 & 55.9 & $37.9-72.8$ & & 706 & 282 & 28.4 & $25.6-31.3$ & \\
\hline $\begin{array}{l}8-21 \\
\text { units/week }\end{array}$ & 1043 & 329 & 31.5 & $28.7-34.5$ & & 820 & 401 & 48.9 & $45.4-52.4$ & & 13 & 4 & 30.8 & $9.1-61.4$ & & 375 & 90 & 24.0 & 19.8-28.7 & \\
\hline $\begin{array}{l}\geq 22 \\
\text { units/week }\end{array}$ & 251 & 70 & 27.9 & $22.4-33.9$ & & 174 & 87 & 50.0 & $42.3-57.7$ & & $3^{* *}$ & 1 & 33.3 & 8.4-90.1 & & 79 & 21 & 26.6 & $17.3-37.8$ & \\
\hline BMI & & & & & 0.007 & & & & & 0.838 & & & & & 0.911 & & & & & 0.139 \\
\hline $\begin{array}{l}\text { Underweight } \\
(<18.5)\end{array}$ & 88 & 36 & 40.9 & $30.5-51.9$ & & 79 & 41 & 51.9 & $40.4-63.3$ & & $1^{* *}$ & 1 & 100.0 & $2.5-1$ & & 43 & 13 & 30.2 & $17.2-46.1$ & \\
\hline $\begin{array}{l}\text { Normal } \\
(18.5-24.9)\end{array}$ & 1731 & 570 & 32.9 & $30.7-35.2$ & & 1494 & 732 & 49.0 & $46.4-51.6$ & & 25 & 12 & 48.0 & $27.8-65.7$ & & 734 & 183 & 24.9 & $21.8-28.2$ & \\
\hline $\begin{array}{l}\text { Overweight } \\
(25-29.9)\end{array}$ & 1409 & 474 & 33.6 & $31.2-36.2$ & & 1297 & 642 & 49.9 & $46.7-52.2$ & & 19 & 9 & 47.4 & $24.4-71.1$ & & 556 & 162 & 29.1 & 25.4-33.1 & \\
\hline Obese ( $\geq 30)$ & 737 & 291 & 39.5 & $35.9-43.1$ & & 855 & 434 & 50.7 & $47.4-52.2$ & & 12 & 7 & 58.3 & $27.7-84.8$ & & 273 & 86 & 31.5 & $26.0-37.4$ & \\
\hline
\end{tabular}

aTested for difference between groups with chi-square test

${ }^{\mathrm{b}}$ Tested for difference between groups with Fischer's exact test
Tested

* Percentages might not fully match to total numbers due to missings. Missings do not exceed $1 \%$

**Insufficient variation in this category 
Table 4 Associations between lifestyle factors and contact to GP with respiratory alarm symptoms for men

\begin{tabular}{|c|c|c|c|c|c|c|c|c|c|c|c|c|c|c|c|c|}
\hline & \multicolumn{4}{|c|}{ At least one respiratory alarm symptom } & \multicolumn{4}{|c|}{ Prolonged coughing } & \multicolumn{4}{|c|}{ Shortness of breath } & \multicolumn{4}{|c|}{ Prolonged hoarseness } \\
\hline & $\overline{O R}$ & Adj. $O^{a}$ & $95 \% \mathrm{Cl}$ & $P$-value ${ }^{c}$ & $\overline{\mathrm{OR}}$ & Adj. $\mathrm{OR}^{\mathrm{a}}$ & $95 \% \mathrm{Cl}$ & $P$-value ${ }^{c}$ & $\overline{\mathrm{OR}}$ & Adj. $\mathrm{OR}^{\mathrm{a}}$ & $95 \% \mathrm{Cl}$ & $P$-value & $\overline{\mathrm{OR}}$ & Adj. $\mathrm{OR}^{\mathrm{a}}$ & $95 \% \mathrm{Cl}$ & $P$-value ${ }^{c}$ \\
\hline Age & & & & $<0.001$ & & & & $<0.001$ & & & & $<0.001$ & & & & $<0.001$ \\
\hline 20-39 & 1 & 1 & & & 1 & 1 & & & 1 & 1 & & & 1 & 1 & & \\
\hline $40-59$ & 1.57 & 1.45 & $1.18-1.78$ & & 1.54 & 1.52 & $1.12-2.07$ & & 1.80 & 1.71 & $1.30-2.25$ & & 2.38 & 2.00 & $1.03-3.86$ & \\
\hline $60-79$ & 2.75 & 2.41 & $1.96-2.95$ & & 2.81 & 2.64 & $1.96-3.55$ & & 3.50 & 3.19 & $2.40-4.24$ & & 4.12 & 3.17 & $1.07-5.89$ & \\
\hline$>80$ & 3.41 & 2.94 & $2.05-4.22$ & & 3.16 & 3.06 & $1.90-4.92$ & & 7.63 & 6.02 & $3.33-10.89$ & & 4.49 & 3.71 & $1.64-8.37$ & \\
\hline \multicolumn{17}{|l|}{ Smoking status } \\
\hline Never & 1 & 1 & & & 1 & 1 & & & 1 & 1 & & & 1 & 1 & & \\
\hline Former & 1.52 & 1.19 & $1.00-1.42$ & & 1.26 & 0.98 & $0.76-1.27$ & & 1.90 & 1.36 & $1.04-1.73$ & & 1.45 & 1.13 & $0.77-1.68$ & \\
\hline Current & 0.62 & 0.59 & $0.49-0.71$ & & 0.53 & 0.50 & $0.39-0.64$ & & 0.78 & 0.67 & $0.51-0.86$ & & 0.61 & 0.65 & $0.40-1.06$ & \\
\hline Alcohol intake & & & & $0.020^{\mathrm{b}}$ & & & & $0.040^{\mathrm{b}}$ & & & & $0.103^{b}$ & & & & $0.892^{b}$ \\
\hline 0 units/week & 1 & 1 & & & 1 & 1 & & & 1 & 1 & & & 1 & 1 & & \\
\hline 1-7 units/week & 0.68 & 0.63 & $0.49-0.71$ & & 0.78 & 0.69 & $0.47-1.00$ & & 0.64 & 0.61 & $0.43-0.87$ & & 1.2 & 1.07 & $0.56-2.07$ & \\
\hline 8-21 units/week & 0.69 & 0.63 & $0.49-0.82$ & & 0.76 & 0.68 & $0.46-1.00$ & & 0.70 & 0.60 & $0.41-0.87$ & & 1.12 & 1.03 & $0.52-2.04$ & \\
\hline$\geq 22$ units/week & 0.63 & 0.59 & $0.48-0.82$ & & 0.61 & 0.54 & $0.33-0.87$ & & 0.68 & 0.62 & $0.39-1.00$ & & 1.19 & 1.15 & $0.50-2.67$ & \\
\hline \multicolumn{17}{|l|}{ Body Mass Index } \\
\hline Underweight $(<18.5)$ & 0.88 & 0.98 & $0.46-2.90$ & & 1.84 & 2.41 & $0.96-6.01$ & & 0.75 & 0.72 & $0.20-4.62$ & & 0.33 & 0.46 & $0.05-3.83$ & \\
\hline Normal (18.5-24.9) & 1 & 1 & & & 1 & 1 & & & 1 & 1 & & & 1 & 1 & & \\
\hline Overweight (25-29.9) & 1.07 & 0.98 & $0.84-1.15$ & & 1.09 & 1.00 & $0.80-1.24$ & & 0.87 & 0.76 & $0.61-0.96$ & & 1.46 & 1.29 & $0.90-1.87$ & \\
\hline Obese $(\geq 30)$ & 1.38 & 1.21 & $1.00-1.46$ & & 1.52 & 1.36 & $1.03-1.79$ & & 0.95 & 0.75 & $0.58-0.98$ & & 1.18 & 1.10 & $0.67-1.79$ & \\
\hline
\end{tabular}

Adj Adjusted
${ }^{a}$ Adjusted for all variables: age, smoking status, alcohol intake and body mass index (except when the variable itself was being examined)

${ }^{\mathrm{b}}$ Only tested for those who drink more than 0 units/week

Bold indicates significance at $5 \%$ level 
Table 5 Associations between lifestyle factors and contact to GP with respiratory alarm symptoms for women

\begin{tabular}{|c|c|c|c|c|c|c|c|c|c|c|c|c|c|c|c|c|}
\hline & \multicolumn{4}{|c|}{ At least one respiratory alarm symptom } & \multicolumn{4}{|c|}{ Prolonged coughing } & \multicolumn{4}{|c|}{ Shortness of breath } & \multicolumn{4}{|c|}{ Prolonged hoarseness } \\
\hline & $\overline{\mathrm{OR}}$ & Adj. $O R^{a}$ & $95 \% \mathrm{Cl}$ & $P$-value ${ }^{c}$ & $\overline{\mathrm{OR}}$ & Adj. $\mathrm{OR}^{\mathrm{a}}$ & $95 \% \mathrm{Cl}$ & $P$-value ${ }^{c}$ & $\overline{\mathrm{OR}}$ & Adj. $O R^{a}$ & $95 \% \mathrm{Cl}$ & $\overline{P \text {-value }}{ }^{c}$ & $\overline{\mathrm{OR}}$ & Adj. $O R^{a}$ & $95 \% \mathrm{Cl}$ & $P$-value ${ }^{c}$ \\
\hline Age & & & & $<0.001$ & & & & $<0.001$ & & & & $<0.001$ & & & & $<0.001$ \\
\hline 20-39 & 1 & 1 & & & 1 & 1 & & & 1 & 1 & & & 1 & 1 & & \\
\hline $40-59$ & 1.48 & 1.47 & $1.21-1.77$ & & 1.33 & 1.4 & $1.05-1.87$ & & 1.52 & 1.49 & $1.17-1.91$ & & 3.51 & 3.41 & $1.95-5.98$ & \\
\hline $60-79$ & 2.51 & 2.52 & $2.08-3.04$ & & 2.23 & 2.33 & $1.76-3.08$ & & 3.09 & 3.31 & $2.56-4.28$ & & 4.61 & 4.74 & $2.73-8.23$ & \\
\hline$>80$ & 2.78 & 2.37 & $1.70-3.32$ & & 2.58 & 2.13 & $1.31-3.46$ & & 3.70 & 3.26 & $2.05-5.18$ & & 3.52 & 3.45 & $1.62-7.37$ & \\
\hline \multicolumn{17}{|l|}{ Smoking status } \\
\hline Never & 1 & 1 & & & 1 & 1 & & & 1 & 1 & & & 1 & 1 & & \\
\hline Former & 1.33 & 1.20 & $1.02-1.41$ & & 1.23 & 1.14 & $0.90-1.45$ & & 1.39 & 1.17 & $0.94-1.47$ & & 0.89 & 0.78 & $0.54-1.13$ & \\
\hline Current & 0.79 & 0.83 & $0.70-0.98$ & & 0.64 & 0.67 & $0.53-0.83$ & & 1.03 & 1.05 & $0.84-1.33$ & & 0.66 & 0.73 & $0.49-1.09$ & \\
\hline Alcohol intake & & & & $<0.001^{\mathrm{b}}$ & & & & $<0.001^{\mathrm{b}}$ & & & & $0.004^{b}$ & & & & $0.016^{b}$ \\
\hline 0 units/week & 1 & 1 & & & 1 & 1 & & & 1 & 1 & & & 1 & 1 & & \\
\hline 1-7 units/week & 0.77 & 0.72 & $0.59-0.88$ & & 0.72 & 0.67 & $0.50-0.88$ & & 0.88 & 0.83 & $0.64-1.06$ & & 0.73 & 0.70 & $0.45-1.10$ & \\
\hline 8-21 units/week & 0.64 & 0.57 & $0.44-0.72$ & & 0.55 & 0.51 & $0.36-0.71$ & & 0.75 & 0.60 & $0.43-0.83$ & & 0.48 & 0.46 & $0.26-0.83$ & \\
\hline$\geq 22$ units/week & 0.53 & 0.48 & $0.28-0.80$ & & 0.59 & 0.54 & $0.28-1.03$ & & 0.80 & 0.72 & $0.31-1.64$ & & 0.59 & 0.59 & $0.17-2.01$ & \\
\hline \multicolumn{17}{|l|}{ Body Mass Index } \\
\hline Underweight $(<18.5)$ & 1.26 & 1.19 & $0.81-1.74$ & & 1.19 & 1.13 & $0.67-1.89$ & & 1.29 & 1.05 & $0.63-1.76$ & & 1.68 & 1.76 & $0.80-3.86$ & \\
\hline Normal (18.5-24.9) & 1 & 1 & & & 1 & 1 & & & 1 & 1 & & & 1 & 1 & & \\
\hline Overweight (25-29.9) & 1.17 & 1.03 & $0.88-1.21$ & & 1.06 & 0.92 & $0.74-1.15$ & & 1.15 & 0.99 & $0.79-1.24$ & & 1.04 & 0.89 & $0.61-1.29$ & \\
\hline Obese $(\geq 30)$ & 1.26 & 1.11 & $0.93-1.33$ & & 1.20 & 1.07 & $0.83-1.38$ & & 1.16 & 0.99 & $0.78-1.26$ & & 1.59 & 1.45 & $0.96-2.21$ & \\
\hline
\end{tabular}

Adj Adjusted
${ }^{a}$ Adjusted for all variables: age, smoking status, alcohol intake and body mass index (except when the variable itself was being examined)

aAdjusted for all variables: age, smoking status, alcohol intake and body mass index (except when the variable itself was being examined)
bOnly tested for those who drink more than 0 units/week

${ }^{\mathrm{b}}$ Only tested for those who drink more than 0 units/week

'Test for trend

Bold indicates significance at $5 \%$ level 


\section{Age}

Among both men and women, a significant trend between increasing age and being more likely to contact a GP with at least one respiratory alarm symptom $\left(P_{\text {trend }}<0.001\right)$, as well as each respiratory alarm symptom $\left(\mathrm{P}_{\text {trend }}<0.001\right)$ was observed (Tables 4 and 5 ).

\section{Smoking status}

Former smoking was a statistically significant determinant for contacting a GP with at least one respiratory alarm symptom for both men $(\mathrm{OR}=1.19,95 \%$ CI 1.001.42) and women $(\mathrm{OR}=1.20,95 \%$ CI 1.02-1.41). Current smokers had significantly lower odds of contacting a GP with at least one respiratory alarm symptom among both men $(\mathrm{OR}=0.59,95 \% \mathrm{CI} 0.49-0.71)$ and women $(\mathrm{OR}=0.83,95 \% \mathrm{CI} 0.70-0.98)$. This was also the case for both genders with prolonged coughing $\left(\mathrm{OR}_{\text {men }}=0.5095 \%\right.$ CI 0.39-0.64; $\mathrm{OR}_{\text {women }}=0.67,95 \%$ CI 0.53-0.83), and among men with shortness of breath $(\mathrm{OR}=0.67,95 \%$ CI 0.51-0.86) (Tables 4 and 5).

\section{Alcohol intake}

Increasing alcohol intake was associated with decreasing odds of contacting a GP with at least one respiratory alarm symptom for both men $\left(P_{\text {trend }}=0.02\right)$ and women $\left(\mathrm{P}_{\text {trend }}<0.001\right)$. The tendency persisted when analysing men with prolonged coughing $\left(\mathrm{P}_{\text {trend }}=0.04\right)$ and when analysing women with prolonged coughing $\left(\mathrm{P}_{\text {trend }}<\right.$ $0.001)$, shortness of breath $\left(\mathrm{P}_{\text {trend }}=0.004\right)$, and prolonged hoarseness $\left(P_{\text {trend }}=0.016\right)$, respectively (Tables 4 and 5).

\section{Body mass index}

Obese men with prolonged coughing were more likely to contact a GP $(\mathrm{OR}=1.36,95 \% \mathrm{CI} 1.03-1.79)$ than men with normal weight. Among men with shortness of breath, overweight $(\mathrm{OR}=0.76,95 \%$ CI $0.61-0.96)$ and obesity (OR $=0.75,95 \%$ CI $0.58-0.98)$ were significantly associated with not opting to contact a GP (Table 4). Among women, no statistically significant associations were observed between BMI and contacting a GP (Table 5).

When analysing the subgroup of people aged 40 years or older, all tendencies and associations persisted for both men and women (data not shown).

\section{Discussion}

\section{Summary of main findings}

In this nationwide study comprising 49706 individuals from the general population, $39.6 \%$ of those reporting RAS had contacted a GP with at least one of the symptoms. The proportion of GP contacts ranged from $27.4 \%$ (prolonged hoarseness) to $49.7 \%$ (shortness of breath). In general, more women than men had contacted a GP with RAS, and the proportion of individuals that contacted a GP increased with increasing age.

Contacting a GP with RAS was significantly associated with lifestyle factors. Current smokers were less likely to contact a GP than never smokers, and the odds of contacting a GP decreased with increasing alcohol intake.

\section{Discussion of results and comparison with existing literature}

Respiratory symptoms are frequently presented in general practice [24], but few studies have estimated the proportion of individuals in the general population who contact a GP with RAS [25-27]. In a population of individuals younger than 60 years, Elliot et al. found that $7.0 \%$ of individuals with coughing and $18.2 \%$ of individuals with shortness of breath contacted a GP [25], proportions much lower than in the present study. Whitaker et al. found that $55.7 \%$ of individuals older than 50 years with persistent cough or hoarseness contacted a GP [26], and Svendsen et al. found that $69.4 \%$ of people older than 40 years with coughing for more than 6 weeks contacted a GP [27], rates that are substantially higher than in the present study. Differences in age groups and time frames might explain some of these differences.

Overall women were more likely to contact general practice about RAS compared to men. The same tendency has been shown for coughing in a previous Danish study [27]. Looking at single symptoms the tendency did however not apply for shortness of breath, where men were more likely to contact a GP. Possible explanations for the gender difference could be to which degree the symptoms interfere with daily life activity or how worrying men and women, respectively, find the symptoms. Women might in general be more aware about the symptoms leading to more contacts to general practice [28]. Men might, however, find that shortness of breath interfere more with their daily living, resulting in more contacts to general practice. These hypotheses will be tested in future studies.

The proportion of individuals with RAS that contacted a GP varied between $27.4 \%$ (prolonged hoarseness) and $49.7 \%$ (shortness of breath). This finding indicates that symptoms defined as cancer alarm symptoms in general practice are not necessarily interpreted as alarming in the general population, but instead registered as a part of everyday life. The positive predictive values of RAS presented in general practice are low [29], entailing that many contacts are required to find the individuals who will actually be diagnosed with lung cancer. In order to decrease the time from first symptom presentation to contact with a GP, additional knowledge and understanding of reasons for healthcare-seeking behaviour are needed. 
Risk of lung cancer increases with age, and individuals older than 40 years, especially smokers, are at higher risk of developing lung cancer than younger individuals $[7,30]$. Furthermore, age is undoubtedly an important factor in the evaluation of patients' symptom presentation in general practice, and decisions about referral for further investigation will often depend on the patient's age. In the present study, the proportion of individuals that contacted a GP because of RAS increased with age, which is in line with the findings of a previous Danish study [27]. To determine the influence of lifestyle factors on establishing GP contact in the age group with increased risk of lung cancer, we analysed the associations for individuals aged 40 years or older. This did, however, not change the associations with lifestyle factors notably.

Current smoking was negatively associated with contacting a GP with RAS. These findings are supported by Smith et al., who found that smoking status was associated with a prolonged interval between the first symptom experience and contacting a GP [13]. The negative association might be due to current smokers interpreting their symptoms as normal [13], or not realising that they have an increased risk of disease [31]. Current smokers might also feel ashamed or fear being stigmatised [12, 32], and therefore opt not to contact a GP.

In the present study, individuals reporting an alcohol intake were less likely to contact a GP to report RAS, and the odds of a person with RAS would contact a GP decreased with increasing alcohol intake. One possible explanation for this is that individuals with no reported alcohol intake have deliberately chosen healthy living and therefore take action when they experience a symptom. Another explanation might be that individuals reporting an alcohol intake are more willing to take a risk than individuals reporting no alcohol intake [33]. These suggestions are hypothetical and should be examined in detail in future studies.

RAS are defined as warnings signs of cancer, but obviously not all symptoms lead to referral for further examination, prescription of medicine or malignant diagnoses. Using a unique personal identification number assigned to all Danish citizens prospective data from the Danish national registers regarding referral to hospital, lung cancer diagnoses and use of medication will be linked to data from the questionnaire. This will enhance the understanding of the significance of RAS in the general population and will provide knowledge about their predictive value for subsequent disease.

\section{Strengths and limitations}

A strength of this study is the large study sample of 100 000 individuals randomly selected from the general
Danish population. A total of $52.2 \%$ answered the questionnaire. The response rate was higher than in two similar population-based studies from the United Kingdom [25, 26], but lower than in a previous Danish study [27]. Although a preponderance of the respondents were women and the respondents were slightly older than the non-respondents, the respondents were fairly representative of the general Danish population. However, differences between the respondents and the non-respondents regarding other parameters, which might include a risk of over- or underestimating the proportion of GP contacts, cannot be eliminated. For more details see Elnegaard et al. [34]. Furthermore it should be acknowledged that despite the large number of participants, the study was unable to detect possible differences between subgroups in regard to e.g. contact to GP with coughing up blood. An even larger sample might have enhanced the statistical power.

Prevalence estimates of symptoms and the proportion of GP contacts might be overestimated if the willingness to complete the questionnaire has been affected by the presence of many RAS or frequent contact to a GP [35, 36]. On the other hand, individuals with many symptoms or GP contacts might not have the surplus energy to complete a questionnaire, which would counterbalance the above-mentioned.

The fact that the questionnaire was web-based might result in selection of the respondents, e.g. exclusion of the elderly. To reduce potential selection bias, individuals without access to a computer, smartphone, or tablet were offered the opportunity to conduct the survey as a telephone interview. Nevertheless, a lower response rate was observed in the oldest age group. This finding might indicate that the telephone interview has not completely compensated for the possible selection. The lower response rate might result in bias, as respondents might be in better health than non-respondents. Thus, the proportion of individuals that contacted a GP among the oldest age group might be even higher than estimated in the present study.

The study participants were asked to recall symptom experiences within the preceding four weeks and whether they at any time had contacted a GP with these symptoms. Recall bias cannot be completely eliminated in questionnaire studies [37]. Some may misplace older symptom experiences in the specified timeframe due to the severity of symptoms or because they had contacted a GP about them [38]. Others may have forgotten about a symptom experience or GP contact, because the symptom turned out to be nothing to worry about or simply due to memory decay [39]. The recall period was chosen because it was found reasonable to assume that people were able to recall symptom experiences and GP contacts fairly accurately within this timespan [40, 41]. 
A general tendency to underreport smoking status, alcohol intake, and weight, and to overreport height, could introduce bias to the self-reported lifestyle factors [42-44]. However, web-based questionnaires have been suggested to enhance the perception of privacy among participants, increasing the reliability of responses regarding sensitive subjects such as lifestyle factors $[45,46]$. Although misclassification cannot be eliminated, the questionnaire was comprehensive and considered a wide range of different symptom experiences and items. Thus, it is unlikely that, for example, questions asked at the beginning of the questionnaire about experience of RAS or contacting a GP about RAS have significantly affected later responses regarding lifestyle factors. A possible misclassification would therefore be non-differentiated [37].

Misunderstanding and misinterpretation of the items are well known weaknesses in questionnaire-based studies. To minimise the risk of misinterpretation, the conceptual framework and wording of the questions were discussed with representatives from three different disciplines: psychology, anthropology, and medical science, prior to the final questionnaire. Furthermore, several pilot tests and a pilot study were conducted to enhance the comprehensibility of the questionnaire [20].

To account for possible confounders, the analyses were adjusted for age, smoking status, alcohol intake, and BMI [22, 23, 47]. We also considered whether other demographic factors could be confounders. Literature regarding demographic factors, healthcare seeking, and the interval between the first symptom experience and contacting a GP has observed few significant associations, but with ambiguous and inconclusive tendencies $[14,25,27,48]$. Thus, demographic factors were not included in the multivariate analyses.

\section{Conclusion and implications}

Among individuals reporting RAS, 39.6\% had contacted a GP. The proportion of individuals who contacted a GP was highest for shortness of breath and lowest for prolonged hoarseness. More women reporting RAS contacted a GP than men, and the proportion that contacted a GP increased with age. Lifestyle factors were significantly associated with contacting a GP with RAS. Current smokers were less likely to contact a GP, and the likelihood of contacting a GP with RAS decreased with increasing alcohol intake.

This study contributes with important estimates of the proportion of individuals in the general population and among different subgroups, who contacted a GP with RAS. A special focus on smokers with RAS who do not contact a GP could lead to earlier presentation and subsequent referral, thereby increasing the chance of diagnosing lung cancer at an earlier stage. One option might be targeting lung cancer awareness campaigns towards current smokers. Other possibilities include increasing the approachability of GPs by encouraging current smokers to initiate contact if they experience RAS [49], and GPs asking about RAS when smokers contact them for other reasons.

Future research should explore considerations ahead of GP contacts and reasons for not contacting a GP when experiencing RAS in the general population and among subgroups. This information might increase understanding of the interval between the first symptom experience and contacting a GP, which might help optimise communication between GPs and patients and contribute to achieving appropriate healthcare seeking among people with cancer alarm symptoms.

\section{Ethical approval}

The Regional Scientific Ethics Committee for Southern Denmark evaluated the project and concluded that the project was not notifiable and could be implemented according to Danish legislation. All participants consented to participate in the study. The participants were clearly informed that there would be no clinical follow-up, and that they should contact their own GP in case of concern or worry. The project has been approved by the Danish Data Protection Agency (journal no. 2011-41-6651).

\section{Availability of data and materials}

Due to data protection regulations of the Danish Data Protection, Statistics Denmark and the Danish Health and Medicines Authority, the access to data is strictly limited to the researchers who have obtained permission for data processing.

\section{Abbreviations \\ BMI: body mass index; CRS: Danish Civil Registration System; GP: general practitioner; RAS: respiratory alarm symptoms.}

Competing interests

The authors declare that they have no competing interests.

\section{Authors' contributions}

LS did the main work in forming the manuscript. DJ, KB and SE participated in the design of the study, development of the questionnaire, the logistics concerning the survey and the drafting of the manuscript. JS participated in the design of the study, development of the questionnaire and drafting of the manuscript. All authors read and approved the final manuscript.

\section{Acknowledgements}

This survey was conducted in collaboration between the University of Southern Denmark and Aarhus University. The project is part of the research portfolio at the Research Centre for Cancer Diagnosis in Primary Care (CaP). Dorte Ejg Jarbøl, Sanne Rasmussen, Kirubakaran Balasubramaniam, Sandra Elnegaard, Rikke Pilsgaard Svendsen, Anette Fischer Pedersen, Rikke Sand Andersen, and Peter Vedsted developed the questionnaire on which the study is based. The authors would like to thank Lise Keller Stark and San Francisco Edit for proofreading the manuscript and Pia Vedsted Larsen for statistical guidance. 


\section{Funding}

We thank the Novo Nordisk Foundation, the Danish Cancer Society, the Danish Council of Independent Research, and the PLU Foundation for financial support. The sponsors have not been involved in the design or development of the study.

Received: 16 September 2015 Accepted: 13 April 2016

Published online: 21 April 2016

\section{References}

1. Ferlay J, Steliarova-Foucher E, Lortet-Tieulent J, Rosso S, Coebergh JW, Comber $\mathrm{H}$, et al. Cancer incidence and mortality patterns in Europe: estimates for 40 countries in 2012. Eur J Cancer. 2013:49(6):1374-403. doi:10.1016/j.ejca.2012.12.027.

2. Walters S, Maringe C, Coleman MP, Peake MD, Butler J, Young N, et al. Lung cancer survival and stage at diagnosis in Australia, Canada, Denmark, Norway, Sweden and the UK: a population-based study, 2004-2007. Thorax. 2013;68(6):551-64. doi:10.1136/thoraxjnl-2012-202297.

3. Torring ML, Frydenberg M, Hansen RP, Olesen F, Vedsted P. Evidence of increasing mortality with longer diagnostic intervals for five common cancers: A cohort study in primary care. Eur J Cancer. 2013;49(9):2187-98. doi:10.1016/j.ejca.2013.01.025.

4. Sundhedsstyrelsen (Danish Health and Medicines Authority). National Cancer Plan II. The National Board of Health, Copenhagen, Denmark. 2005. https://sundhedsstyrelsen.dk/da/sundhed/folkesygdomme/kraeft/nationaleplaner/kraeftplan-ii. Accessed 12 Mar 2015.

5. NICE. Referal Guidelines for suspected cancer. National Institute for Health and Care Excellence. 2005. http://www.nice.org.uk/guidance/cg27/. Accessed 15 Jan 2015.

6. NICE. Lung cancer: The diagnosis and treatment of lung cancer. National Institute for Health and Care Excellence. 2011. http://www.nice.org.uk/ guidance/cg121. Accessed 4 Dec 2014.

7. Sundhedsstyrelsen (Danish Health and Medicines Authority). Indgange til Lungekræftpakken. The National Board of Health, Copenhagen, Denmark. 2012. http://sundhedsstyrelsen.dk/da/sygdom-og-behandling/kraeft pakkeforloeb/beskrivelser. Accessed 12 Mar 2015.

8. Barrett J, Hamilton W. Pathways to the diagnosis of lung cancer in the UK: a cohort study. BMC Fam Pract. 2008;9:31. doi:10.1186/1471-2296-9-31.

9. Guldbrandt LM. The effect of direct referral for fast CT scan in general practice. A clinical, cluster-randomised trial. In: PhD Thesis. Aarhus: Aarhus University; 2014.

10. Beckles MA, Spiro SG, Colice GL, Rudd RM. Initial evaluation of the patient with lung cancer: symptoms, signs, laboratory tests, and paraneoplastic syndromes. Chest. 2003:123(1 Suppl):97s-104s.

11. Lovgren M, Levealahti H, Tishelman C, Runesdotter S, Hamberg K. Time spans from first symptom to treatment in patients with lung cancer- the influence of symptoms and demographic characteristics. Acta Oncol. 2008; 47(3):397-405. doi:10.1080/02841860701592392.

12. Corner J, Hopkinson J, Roffe L. Experience of health changes and reasons for delay in seeking care: a UK study of the months prior to the diagnosis of lung cancer. Soc Sci Med. 2006;62(6):1381-91. doi:10.1016/j.socscimed.2005.08.012.

13. Smith SM, Campbell NC, MacLeod U, Lee AJ, Raja A, Wyke S, et al. Factors contributing to the time taken to consult with symptoms of lung cancer: a cross-sectional study. Thorax. 2009;64(6):523-31. doi:10.1136/thx.2008.096560

14. Macleod U, Mitchell ED, Burgess C, Macdonald S, Ramirez AJ. Risk factors for delayed presentation and referral of symptomatic cancer: evidence for common cancers. Br J Cancer. 2009;101 Suppl 2:S92-S101. doi:10.1038/sj.bjc.6605398

15. Tromp DM, Brouha XD, De Leeuw JR, Hordijk GJ, Winnubst JA. Psychological factors and patient delay in patients with head and neck cancer. Eur J Cancer. 2004;40(10):1509-16. doi:10.1016/j.ejca.2004.03.009.

16. Chatwin J, Sanders C. The influence of social factors on help-seeking for people with lung cancer. Eur J Cancer Care. 2013;22(6):709-13. doi:10.1111/ecc.12078.

17. Tod AM, Craven J, Allmark P. Diagnostic delay in lung cancer: a qualitative study. J Adv Nurs. 2008:61(3):336-43. doi:10.1111/j.1365-2648.2007.04542.x.

18. Thygesen LC, Daasnes C, Thaulow I, Bronnum-Hansen H. Introduction to Danish (nationwide) registers on health and social issues: structure, access, legislation, and archiving. Scand J Public Health. 2011;39(7 Suppl):12-6.
19. Hamilton W, PetersTJ, Round A, Sharp D. What are the clinical features of lung cancer before the diagnosis is made? A population based case-control study. Thorax. 2005;60(12):1059-65. doi:10.1136/thx.2005.045880.

20. Rasmussen S, Sondergaard J, Larsen PV, Balasubramaniam K. The Danish Symptom Cohort: Questionnaire and Feasibility in the Nationwide Study on Symptom Experience and Healthcare-Seeking among 100000 Individuals. Int J Family Med. 2014;2014:187280. doi:10.1155/2014/187280.

21. World Health Organization (WHO). BMI Classification. World Health Organization. 2006. http://apps.who.int/bmi/index.jsp?introPage=intro_3. html. Accessed 6. January 2015.

22. Zang EA, Wynder EL. Reevaluation of the confounding effect of cigarette smoking on the relationship between alcohol use and lung cancer risk, with larynx cancer used as a positive control. Prev Med. 2001:32(4):359-70. doi:10.1006/pmed.2000.0818

23. Gupta S, Hassan S, Bhatt VR, Abdul Sater H, Dilawari A. Lung cancer trends: smoking, obesity, and sex assessed in the Staten Island University's lung cancer patients. Int J Gen Med. 2014:7:333-7. doi:10.2147/ijgm.s55806.

24. Moth G, Olesen F, Vedsted P. Reasons for encounter and disease patterns in Danish primary care: changes over 16 years. Scand J Prim Health Care. 2012 30(2):70-5. doi:10.3109/02813432.2012.679230.

25. Elliott AM, McAteer A, Hannaford PC. Revisiting the symptom iceberg in today's primary care: results from a UK population survey. BMC Fam Pract. 2011;12:16. doi:10.1186/1471-2296-12-16.

26. Whitaker KL, Scott SE, Winstanley K, Macleod U, Wardle J. Attributions of cancer 'alarm' symptoms in a community sample. PLoS One. 2014;9(12): e114028. doi:10.1371/journal.pone.0114028.

27. Svendsen RP, Jarbol DE, Larsen PV, Stovring H, Hansen BL, Soendergaard J. Associations between health care seeking and socioeconomic and demographic determinants among people reporting alarm symptoms of cancer: a population-based cross-sectional study. Fam Pract. 2013;30(6):65565. doi:10.1093/fampra/cmt036

28. Briscoe ME. Why do people go to the doctor? Sex differences in the correlates of GP consultation. Soc Sci Med. 1987;25(5):507-13. doi:10.1016/ 0277-9536(87)90174-2.

29. Hamilton W. The CAPER studies: five case-control studies aimed at identifying and quantifying the risk of cancer in symptomatic primary care patients. Br J Cancer. 2009;101 Suppl 2:S80-6. doi:10.1038/sj.bjc.6605396.

30. Walter FM, Rubin G, Bankhead C, Morris HC, Hall N, Mills K, et al. Symptoms and other factors associated with time to diagnosis and stage of lung cancer: a prospective cohort study. Br J Cancer. 2015. doi:10.1038/bjc.2015.30.

31. Weinstein ND, Marcus SE, Moser RP. Smokers' unrealistic optimism about their risk. Tob Control. 2005;14(1):55-9. doi:10.1136/tc.2004.008375.

32. Chapple A, Ziebland S, McPherson A. Stigma, shame, and blame experienced by patients with lung cancer: qualitative study. BMJ (Clinical research ed). 2004:328(7454):1470. doi:10.1136/bmj.38111.639734.7C.

33. Dave D, Saffer H. Alcohol demand and risk preference. J Econ Psychol. 2008, 29(6):810-31. doi:10.1016/j.joep.2008.03.006.

34. Elnegaard S, Andersen RS, Pedersen AF, Larsen PV, Søndergaard J, Rasmussen S, et al. Self-reported symptoms and healthcare seeking in the general population - exploring "The Symptom Iceberg". BMC Public Health. 2015. doi:10.1186/s12889-015-2034-5.

35. Galea S, Tracy M. Participation rates in epidemiologic studies. Ann Epidemiol. 2007:17(9):643-53. doi:10.1016/j.annepidem.2007.03.013.

36. Nakash RA, Hutton JL, Lamb SE, Gates S, Fisher J. Response and nonresponse to postal questionnaire follow-up in a clinical trial-a qualitative study of the patient's perspective. J Eval Clin Pract. 2008;14(2):226-35. doi: 10.1111/j.1365-2753.2007.00838.x.

37. Rothman KJ. Epidemiology: An Introduction. New York: Oxford University Press; 2012

38. McColl E. Best practice in symptom assessment: a review. Gut. 2004;53 Suppl 4:iv49-54

39. Jenkins P, Earle-Richardson G, Slingerland DT, May J. Time dependent memory decay. Am J Ind Med. 2002;41(2):98-101.

40. Steen N, Hutchinson A, McColl E, Eccles MP, Hewison J, Meadows KA, et al. Development of a symptom based outcome measure for asthma. BM (Clinical research ed). 1994:309(6961):1065-8.

41. Stull DE, Leidy NK, Parasuraman B, Chassany O. Optimal recall periods for patient-reported outcomes: challenges and potential solutions. Curr Med Res Opin. 2009;25(4):929-42. doi:10.1185/03007990902774765.

42. Connor Gorber S, Schofield-Hurwitz S, Hardt J, Levasseur G, Tremblay M. The accuracy of self-reported smoking: a systematic review of the relationship 
between self-reported and cotinine-assessed smoking status. Nicotine Tob Res. 2009;11(1):12-24. doi:10.1093/ntr/ntn010.

43. Connor Gorber S, Tremblay M, Moher D, Gorber B. A comparison of direct vs. self-report measures for assessing height, weight and body mass index: a systematic review. Obes Rev. 2007;8(4):307-26. doi:10.1111/j.1467-789X.2007.00347.x.

44. Heller WD, Scherer G, Sennewald E, Adlkofer F. Misclassification of smoking in a follow-up population study in southern Germany. J Clin Epidemiol. 1998:51(3):211-8.

45. Crutzen R, Goritz AS. Social desirability and self-reported health risk behaviors in web-based research: three longitudinal studies. BMC Public Health. 2010;10:720. doi:10.1186/1471-2458-10-720.

46. Del Boca FK, Darkes J. The validity of self-reports of alcohol consumption: state of the science and challenges for research. Addiction (Abingdon, England). 2003;98 Suppl 2:1-12

47. Dela Cruz CS, Tanoue LT, Matthay RA. Lung cancer: epidemiology, etiology, and prevention. Clin Chest Med. 2011;32(4):605-44. doi:10.1016/j.ccm.2011.09.001.

48. Neal RD, Allgar VL. Sociodemographic factors and delays in the diagnosis of six cancers: analysis of data from the "National Survey of NHS Patients: Cancer". Br J Cancer. 2005;92(11):1971-5. doi:10.1038/sj.bjc.6602623.

49. Power $E$, Wardle J. Change in public awareness of symptoms and perceived barriers to seeing a doctor following Be Clear on Cancer campaigns in England. Br J Cancer. 2015. doi:10.1038/bjc.2015.32.

Submit your next manuscript to BioMed Central and we will help you at every step:

- We accept pre-submission inquiries

- Our selector tool helps you to find the most relevant journal

- We provide round the clock customer support

- Convenient online submission

- Thorough peer review

- Inclusion in PubMed and all major indexing services

- Maximum visibility for your research

Submit your manuscript at www.biomedcentral.com/submit
Biomed Central 